\begin{tabular}{|c|c|}
\hline Title & $\begin{array}{l}\text { Impact of micro-porous layer on liquid water distribution at the catalyst lay er interface and cell performance in a } \\
\text { polymer electrolyte membrane fuel cell }\end{array}$ \\
\hline Author(s) & Tabe, Y utaka; A oy ama, Y usuke; Kadowaki, Kazumasa; Suzuki, Kengo; Chikahisa, Takemi \\
\hline Citation & $\begin{array}{l}\text { Journal of Power Sources, 287, } 422-430 \\
\text { https://doi.org/10.1016/.j.jpowsour.2015.04.095 }\end{array}$ \\
\hline Issue Date & 2015-08-01 \\
\hline Doc URL & http:/hdl .handle.net/2115/66894 \\
\hline Rights & $\begin{array}{l}\text { () 2015. This manuscript version is made available under the CC-BY-NC-ND } 4.0 \text { license } \\
\text { http://reativecommons.org/icenses/by-nc-nd/4.0/ }\end{array}$ \\
\hline Rights(URL) & https://creativecommons.org/icenses/by-nc-nd/4.0/ \\
\hline Type & article (author version) \\
\hline File Information & Manuscript.pdf \\
\hline
\end{tabular}

Instructions for use 


\title{
Impact of micro-porous layer on liquid water distribution at the catalyst layer interface and cell performance in a polymer electrolyte membrane fuel cell \\ Yutaka Tabe*, Yusuke Aoyama, Kazumasa Kadowaki, Kengo Suzuki, Takemi Chikahisa Division of Energy and Environmental Systems, Graduate School of Engineering, Hokkaido University, N13 W8, Kita-ku, Sapporo, Hokkaido 060-8628, Japan \\ * Corresponding author. Tel.: +81 11706 6381; fax: +81 117067889. \\ E-mail address: tabe@eng.hokudai.ac.jp; N13 W8, Kita-ku, Sapporo 060-8628, Japan.
}

\begin{abstract}
In polymer electrolyte membrane fuel cells, a gas diffusion layer (GDL) with a micro-porous layer (MPL) gives better anti-flooding performance than GDLs without an MPL. To investigate the function and mechanism of the MPL to suppress water flooding, the liquid water distribution at the cathode catalyst layer (CL) surface are observed by a freezing method; in the method liquid water is immobilized in ice form by rapid freezing, followed by disassembling the cell for observations. The ice covered area is quantified by image processing and cells with and without an MPL are compared. The results show that the MPL suppresses water accumulation at the interface due to smaller pore size and finer contact with the $\mathrm{CL}$, and this results in less water flooding. Investigation of ice formed after $-10{ }^{\circ} \mathrm{C}$ cold start shutdowns and the temporary performance deterioration at ordinary temperatures also indicates a significant influence of the liquid water accumulating at the interface. The importance of the fine contact between CL and MPL, the relative absence of gaps, is demonstrated by a gas diffusion electrode (GDE) which is directly coated with catalyst ink on the surface of the MPL achieving finer contact of the layers.
\end{abstract}

\section{Highlights}

- Liquid water distribution at the cathode catalyst layer (CL) surface is observed.

- Performance deteriorates due to the liquid water accumulated on the CL surface.

- The MPL reduces liquid water accumulation between the CL and the MPL.

- Cold startup induces much water accumulation and temporary performance deterioration.

- A gas diffusion electrode with fine CL to MPL contact mitigates the flooding.

Keywords: PEM fuel cell, Micro-porous layer, Liquid water distribution, Flooding, Image analysis, Water management

\section{Introduction}

The polymer electrolyte membrane fuel cell (PEFC) is a promising power source for automobiles and distributed cogeneration systems (the so-called combined heat and power; CHP) with high efficiency and clean emission characteristics. For practical uses of PEFC, water flooding at high current density conditions is one of the major issues to be improved, because flooding deteriorates efficiency and maximum power output due to limiting the supply of reactants to the reaction area by the water accumulated in the cell. It is generally known that a micro-porous layer (MPL) contributes to better water removal from the cathode catalyst layer (CL) and to improvements in the cell performance [1-4]. The MPL introduces a 
fine carbon layer between the CL and gas diffusion layer (GDL), and has smaller pore sizes than the GDL. However, the precise mechanism of water transport phenomena arising with the MPL is not fully understood.

Early computational studies reported that the MPL improves water removal from the cathode GDL by increasing the hydraulic pressure differential across the membrane [1], and that the MPL acts like a valve that pushes water away from the cathode and towards the anode through the membrane [2]. Gostick et al. estimated the water saturation and capillary pressure for GDLs with and without an MPL from the measured conditions of the liquid water breakthrough at the porous layers, and suggested that the efficacy of the MPL is due to finite-size effects related to invasion percolation in thin GDLs where liquid water percolation through the MPL results in limited access of water to the GDL inlet face [5]. Owejan et al. compared the cell performance using various types of GDLs with and without MPLs, analyzed the vapor flux driven by the saturation pressure gradient in the cathode diffusion layer due to the temperature gradient, and proposed that the primary role of the MPL is preventing condensed water from accumulating near the cathode CL surface [6]. The impact of interfacial gaps between the CL and the MPL was also noted, and it was indicated that these gaps may act as water accumulation sites and prevent the reactant gases from reaching active sites in the CL [7-9]. The morphology of the CL and MPL surfaces has been characterized in detail [7], and the effects of the interfacial morphology on the ohmic, thermal, and mass-transport losses were investigated numerically [8,9]. To elucidate the mechanism of water transport phenomena experimentally, some work has attempted to visualize the liquid water in a PEFC [10-14]. For the cross-sectional visualization of the liquid water inside porous structures like GDL, published studies have commonly used neutron radiography $[10,11]$ and X-ray radiography $[12,13]$. Vapor condensation and liquid water breakthrough in the porous structures at the surface of the CL were observed by environmental scanning electron microscopy [14]. Here, the experiments indicated that an MPL reduces the saturation level of water on the CL surface [11,13,14], however the spatial resolution of the liquid water visualization has been inadequate and the structure of the cells investigated are different from commonly-used cells.

Recently, the authors observed the cross-sectional distribution of liquid water in the vicinity of a cathode MPL by the freezing method and by cryo-scanning electron microscopy. The freezing method immobilizes the liquid water in the cell as ice forms by decreasing the temperature in a short time, and the cryo-SEM visualizes the ice distribution in the MPL at high resolutions at $-150{ }^{\circ} \mathrm{C}$ [15]. The research has however not resolved a number of issues, including the effects of the MPL on in-plane distribution of liquid water at the CL surface and the overall cell performance, a better understanding of which would enable further advances in the water management.

This study observed the liquid water distribution at the cathode CL surface using the freezing method, and quantified the amount of ice covered areas on the surface of the CL with image analysis for various operating conditions using GDLs with and without an MPL. The cell performance was also measured, and the role of the MPL in suppressing water flooding is discussed by comparing the observed water distribution on the CL surface and the measured flooding characteristics. Further, the following two phenomena related to the impact of the MPL and the liquid water distribution at the CL surface on the tolerance to flooding were 
investigated experimentally. The authors have reported that the shutdown at $-10{ }^{\circ} \mathrm{C}$ cold startup induces a temporary performance deterioration in the subsequent operation at ordinary temperature, and that this is caused by the liquid water melted from the ice formed at the interface between the cathode CL and the MPL [16]. To validate that there is a larger ice covered area, which potentially makes much water accumulate at the interface after the cold startup, the ice distribution on the CL surface after the $-10{ }^{\circ} \mathrm{C}$ cold start shutdown was quantified and compared with the ice distribution after operation at ordinary temperatures. As the second related phenomenon, the effect of the interfacial nature between the CL and the MPL was examined by comparing the polarization curves of two types of MEAs with different structures of the CL and MPL interface.

\section{Experiments and image analysis}

\subsection{Experimental apparatus and methods}

A small single cell with an active area of $1.8 \mathrm{~cm}^{2}(0.9 \mathrm{~cm} \times 2.0 \mathrm{~cm})$ was used to ensure simple assembly and disassembly, and rapid cooling of the cell for the freezing method. A photo of a bipolar plate of the cell is shown in Fig. 1, together with a photo of the arrangements inside the thermostatic chamber used for the rapid cooling. The bipolar plate is made of copper overlaid with gold, and has five straight gas channels; the width of the channels and the lands were $1.0 \mathrm{~mm}$, and the channel depth was $0.5 \mathrm{~mm}$. The bipolar plates with stainless-steel end-plates for the anode and cathode sides sandwiched a catalyst-coated membrane (CCM) in the center and gas diffusion layers (GDLs) on both sides. The CCM was GORE-TEX (PRIMEA 5570), and two types of GDLs were used: $235 \mu \mathrm{m}$ thick carbon paper with a hydrophobic MPL (SIGRACET®GDL 25BC), which was used for both of the anode and cathode sides, and $190 \mu \mathrm{m}$ thick carbon paper without an MPL (SIGRACET®GDL 25BA) for the cathode side. Pure hydrogen as the anode gas and air as the cathode gas were supplied in the same direction, and the gas humidity was controlled by the bubbler temperature. The cell was set in a thermostatic chamber (HITACHI, EC-25MTP) with a controllable temperature range of -40 to $100{ }^{\circ} \mathrm{C}$, and the temperatures of the cell and the supplied gas were controlled by the chamber temperature. The cell resistance was measured by an alternating impedance meter at $1 \mathrm{kHz}$. The cell voltage, cell resistance, and the temperatures of both cell and supplied gas were recorded digitally.

The procedures of the experiments are outlined in Fig. 2. After a conditioning process to enhance the performance of the CCM, a dry purge, lasting until the cell resistance reached $0.16 \Omega \mathrm{cm}^{2}$, with dry nitrogen was conducted to remove all liquid water from the cell, and then the cell performance was measured at $35^{\circ} \mathrm{C}$. In the performance measurements, the flow

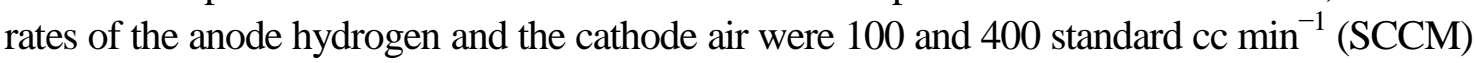
respectively, and the cell and humidification conditions of the gases were: a cell temperature of $35^{\circ} \mathrm{C}$ and bubbler temperatures of $35^{\circ} \mathrm{C}$ (relative humidity of gases $100 \%$ ) and $30^{\circ} \mathrm{C}(\mathrm{RH}$ $76 \%)$. Then, for direct observations of the inside of the cell, the operation was stopped and the water distribution was investigated with the freezing method $[15,17]$. In this method, the cell is cooled to $-30^{\circ} \mathrm{C}$ in the thermostatic chamber for about $30 \mathrm{~min}$ to capture the liquid water in ice form. It took less than $4 \mathrm{~min}$ for the cell to be cooled to $0^{\circ} \mathrm{C}$. The authors have confirmed 
that the water moved little during the cooling process in an experiment limited to determine this [17]. Thus, the freezing method immobilizes the condensed water in the cell and makes it possible to observe the water distribution directly from the ice distribution. The cell was disassembled into its component parts at $-30{ }^{\circ} \mathrm{C}$ in the thermostatic chamber and the surface of the CCM as removed from the cell was observed by an optical microscope (LEICA, Z16APO) installed in the thermostatic chamber, as shown in Fig. 1. The thermostatic chamber has a window and two holes at the front for the handling, which enable the disassembling of the cell and observations of the component surfaces of the cell using the optical microscope at the freezing (below $0{ }^{\circ} \mathrm{C}$ ) temperature. Here, the focus and the observation positions were adjusted using a motor-driven XYZ stage also installed in the low-temperature environment. The CCM surface was observed again after the cell was heated to $30{ }^{\circ} \mathrm{C}$ to compare photos with and without ice.

The cold start experiments were also conducted to determine the effect of the liquid water distribution at the CL surface on the cell performance, and the procedures are also outlined in Fig. 2. Before cold start operation, humidified nitrogen was supplied to control the initial state of residual water in the cell after the dry purge process. The wet purge was continued to achieve an equilibrium state in the CCM until resistance at a steady level was established, here humidified nitrogen with relative humidity $24 \%$ was used in the wet purge at $60{ }^{\circ} \mathrm{C}$. Full details of the method of the cold start experiment are in Ref. [16]. After the wet purge, the cell and the chamber were cooled to $-10{ }^{\circ} \mathrm{C}$, and the cell operation was then started and maintained at a constant current density until the cell shut down. During the cold startup, dry hydrogen and dry air were supplied at 30 and 70 SCCM respectively. Then, observations of the CCM surface was made in the manner described above, as shown in Fig. 2. In the investigation of the cell performance at ordinary temperatures after the cold start shutdown, the cell was heated to $35^{\circ} \mathrm{C}$, and the cell performance was determined for comparison with the performance before the cold startup (Fig. 2).

\subsection{Image analysis methods}

To evaluate the amount of condensed water at the CCM surface, micrographs of the CCM surface with the frozen water were processed into binary images. Fig. 3 (a) is an example of a micrograph of the cathode CL surface of the CCM after the cell operation. Ice is seen in white (ice) and dark (shadows cast by the ice) areas. Fig. 1(b) shows an image histogram for the brightness of Fig. 3(a). As ice areas correspond to both very bright and very dark regions, the lower and higher ranges of the brightness appear to correspond to the CL surface with ice. Here, two thresholds were applied to identify the ice for approximate estimates; the threshold $t_{d}$ is the value intermediate between the average and the minimum, and $t_{b}$ is the value between the average and the maximum of the brightness. Setting the thresholds from the histogram using the average, the minimum, and the maximum values avoids the binary image being affected by lighting intensity which may depend on the light source conditions. In Fig. 3(c), the pixels with brightness lower than the threshold $t_{d}$ are represented by white, and it was confirmed that the white regions correspond to the ice appearing darker in Fig. 3(a). The white regions of Fig. 3(d) correspond to the brightness higher than the threshold $t_{b}$ in Fig. 3(a). The areas covered by ice are identified by a combination of the white areas in Figs. 3(c) and (d), 
and are shown in Fig. 3(e). This method is not completely accurate and it does not quantify the ice thickness, however it is useful to evaluate the differences in the ice distribution on the CL surface for the various conditions investigated here.

Fig. 4 is an example of binary images of the ice at the sub-zero temperature (Fig. 4(a)) and without the ice after heating to $30{ }^{\circ} \mathrm{C}$ (Fig. 4(b)). The white particles in Fig. 4(b) appear to be GDL fibers and other components appearing as "noise" sticking to the surface. The cell as shown in the images in Fig. 4 was operated for 1 hour before the observation without the MPL. The humidity of the supplied gases was $76 \% \mathrm{RH}$ and the applied constant current density was $0.7 \mathrm{~A} \mathrm{~cm}^{-2}$. In the image in Fig. 4(c) the white areas in (b) are subtracted from the white areas in (a), and Fig. 4(c) may be assumed to show the ice covered areas. The analysis was made for the areas under the channels and under the lands, and the percentage of the ice covered area was calculated by the following equation:

$$
\text { Percentage of ice covered area }(\%)=\frac{N_{\text {ice }}}{N_{\text {all }}-N_{\text {noise }}} \times 100
$$

Here, $N_{\text {ice }}$ is the number of white pixels (with ice) in the subtracted image in Fig. $4(\mathrm{c}), N_{\text {noise }}$ is the number of white pixels in Fig. 4(b) (noise), and $N_{\text {all }}$ is the total number of pixels of the examined area. In this equation, the noise was omitted from the analysis.

\section{Results and discussion}

\subsection{Effect of the MPL on the cell performance}

The polarization curves for the GDLs with and without the MPL are shown in Fig. 5. The humidification conditions of both the anode hydrogen and the cathode air shown here are $100 \%$ and $76 \%$ relative humidity $(\mathrm{RH})$, with the cell temperature at $35^{\circ} \mathrm{C}$. The measurements applied a constant current which was increased from $0.0 \mathrm{~A}$, and the plot shows the stable voltage at each current level after operation at this current for a couple of minutes. For the GDL with the MPL, the cell voltages are similar, and higher than those without the MPL at both relative humidity conditions investigated here. The difference is larger at higher current density conditions and also at the higher relative humidity condition. The curve for the GDL without the MPL at 100\% RH deviates from the curves for that with the MPL by around 0.4 $\mathrm{A} \mathrm{cm}{ }^{-2}$, and reaches a limiting current density around $0.9 \mathrm{~A} \mathrm{~cm}^{-2}$. This indicates that the difference can be attributed to the difference in the concentration overpotential due to the MPL. The GDL with the MPL tends to suppress flooding, and a sufficient oxygen supply is maintained even under higher liquid water production conditions. Without the MPL there is a clear voltage drop at the higher current densities and the higher humidity condition, and this may be caused by a deterioration in the oxygen supply due to the produced water.

Fig. 6 shows the changes in the cell voltage and the cell resistance after the start of the power generation at two constant current densities for the GDLs with and without the MPL. The humidity of the both gases was $100 \% \mathrm{RH}$, and the applied constant current densities were (a) 0.5 and (b) $0.7 \mathrm{~A} \mathrm{~cm}^{-2}$. During the 1 hour of operation, the cell voltages for the GDL with 
the MPL are maintained at high and stable values at both current densities, while the voltages for the GDL without the MPL are lower and decrease gradually with time. The difference in the cell voltages is larger at the higher current density, $0.7 \mathrm{~A} \mathrm{~cm}^{-2}$, as suggested by the results in Fig. 5. The cell resistances for the GDLs with and without the MPL are similar at both current densities, suggesting that the difference in the cell voltages is less affected by the ohmic resistance loss. These results also support the idea that the MPL functions to suppress the deterioration in the cell performance caused by flooding.

\subsection{Observation of ice distribution on the CL surface}

To investigate the reasons for the differences in the cell performance with and without an MPL, the water distribution in the cell was observed in the form of ice by the freezing method as outlined above. Fig. 7 shows a micrograph of the cathode CL surface and the processed images for the cell with the MPL. The cell in Fig. 7 was operated at the current density of 0.7 A cm${ }^{-2}$ for 1 hour, with the humidity of both gases at $100 \% \mathrm{RH}$, and the surface of the cathode was evaluated. After disassembling the cell, there was very little ice to be seen on the surface of the MPL, the surface facing the CL, and in the following only the ice on the CL surface was analyzed. Fig. 7(a) is the micrograph of the cathode CL surface, and Figs. 7(b) to (d) are binary images: (b) with ice, (c) without ice, and (d) subtracted (the noise appearing as white in (c) is subtracted from the (b) image). These images show that the ice covered area is significantly smaller under lands than under channels.

The average percentages of ice covered areas are summarized in Table 1 for four data sets (micrographs and images) at different positions. The data sets are labeled in order from the up to down stream, and the number 4 location is for the micrograph and the images in Fig. 7. The percentages in the image with ice were calculated using the binary image with ice, e.g. Fig. 7(b), and they include the percentages of ice and noise. The percentages calculated using the subtracted image were calculated by the subtracted images, like Fig. 7(d) with the equation in section 2.2 and the binary images without ice, like Fig. 7(c), and the areas correspond to the percentages of ice only. Table 1 shows that the differences between these two sets of percentages are small, and it may be assumed that the effects of the noise are negligible. The data in Table 1 gives the percentages for the areas under the channels, the lands, and the ice ratios for both of the areas together. The area percentages of ice clearly show the location-related differences, and similar distributions at all of the positions: the ranges of the percentages calculated using the subtracted image under the channels, the lands, and for both areas together are from 10.3 to $15.3 \%, 0.9$ to $2.3 \%$, and 6.3 to $8.4 \%$, respectively.

Fig. 8 shows a micrograph of the surface of the cathode CL and the processed images without the MPL. The percentages of ice covered areas are detailed in Table 2, where the number 4 location is for the micrograph and the images in Fig. 8. There is a large amount of noise in the image without ice particularly under the lands, as suggested by Fig. 8(c), and this causes the noticeable differences between the percentages in the image with ice and the percentages calculated using the subtracted image in Table 2. The subtracted image and the calculated percentages show that the ice covered areas under channels and under lands are similar, and a uniform distribution of ice is observed. The ranges of the calculated percentages of ice covered areas under the channels, the lands, and both of the areas are from 4.5 to $12.3 \%$, 
8.0 to $13.0 \%$, and 6.5 to $12.6 \%$ respectively. The analysis of the results with and without the MPL indicates that the MPL limits the water amount at the interface between the CL and the MPL, and that the water amount is more significantly limited under the lands than under the channels, here this may be assumed to be due to the higher contact pressure under lands. The higher percentages of ice covered areas on the CL surface under the lands for the GDL without the MPL is considered to be caused by more and larger spaces at the interface due to the rougher surface of the GDL.

Fig. 9 shows examples of the subtracted images of the cathode CL surface for the cell with the MPL for the current densities 0.7 and $0.5 \mathrm{~A} \mathrm{~cm}^{-2}$ and the relative humidities 100 and $76 \%$. With the MPL, relatively-large ice areas tend to be located non-uniformly under the channels; while without the MPL, a number of smaller ice covered areas are distributed widely on the CL surface. The reasons for the differences in the ice covered areas are considered to be that the condensed water growth is restricted in the thickness direction by the hydrophobic MPL, and without the MPL thicker water accumulations grow and intrude into the GDL pores. The average percentages of ice covered areas calculated using the equation in section 2.2 at four different positions are plotted in Fig. 10(a) for the ice covered ratios under the channels, under the lands, and for both of these areas of the cell with the MPL. The figure clearly shows that with the MPL the ice covered area is significantly smaller under the lands than under the channels at all of the conditions, and the area ratio is higher with the higher current density and relative humidity of the supplied gases. Fig. 10(b) shows the ice covered areas for the cell without the MPL. Without the MPL the ice covered areas under the channels and under the lands are similar, although the percentage varies somewhat due to the influence of the noise, as suggested in Fig. 8(c). A comparison of Figs. 10(a) and (b) indicates that the ice covered area on all of the surfaces is larger without the MPL than with the MPL, and this corresponds to the cell voltages shown in Fig. 5: the higher total ice covered area percentages may be assumed to suggest a cause of the reduction with the cell voltage at both current densities, 0.5 and $0.7 \mathrm{~A} \mathrm{~cm}^{-2}$. The smaller amounts of water under lands indicated by the smaller ice covered areas for the GDL with the MPL would in turn reduce the water covered area on the overall CL surface, particularly as there is little water accumulation directly under the lands, and this may contribute to suppression of the voltage deterioration. Overall, the photographic analysis in this study is effective to evaluate the approximate effect of the ice covered area on the cell performance, and the detailed comparison shows that the cell voltage tends to deteriorate more at the ice covered area in the cell without the MPL. This may be explained by the following: widely-distributed thicker water volumes intruding into the GDL are more likely to impede the oxygen supply, and the condensed water is distributed more widely in the GDL when the access of water to the GDL inlet face is not limited by the dense pore structure of an MPL. It may be concluded that without the MPL more liquid water accumulates at the interface between the CL and the GDL, and this difference in the water amounts at the interface would be a cause of the differences in cell performance, i.e. the cell voltage becoming higher with an MPL than without an MPL.

\subsection{Mechanism of the MPL induced improvements in cell performance}


The experimentally suggested details of the liquid water distribution at the surface of the cathode CL with and without an MPL are shown in Fig. 11. For the GDL with the MPL (Fig. 11(a)), the water produced in the CL passes through the MPL and is removed from the CL surface to the GDL, while oxygen from the air is continuously supplied from the channel to the CL. The MPL may transport the produced water in vapor form because of the large vapor diffusion potential with a steep temperature gradient in the MPL [6,15]. However, at the interface between the CL and MPL the produced water accumulates in liquid form particularly at high current density conditions, as shown in the previous section. This may be because there are non-uniformly-distributed small gaps between the CL and MPL arising due to the surface roughness of the CL and the MPL. The water generated during the cell operation condenses more easily here than in the submicron scale pores in the MPL. Under the lands, the gaps at the CL and MPL interface are fewer and restricted by a higher contact pressure; under the channels, there is some increase in condensed water accumulation with the deformation in the GDL. This would explain why a smaller water amount is observed under lands than under channels in the GDL with the MPL. At the interface between the CL and the GDL in the cell without the MPL (Fig. 11(b)), there are larger spaces at the interface between the CL and GDL for water to accumulate due to the rougher GDL surface (rougher than the MPL surface), and more condensed water under the lands with the higher contact pressure as well as under the channels. The larger areas of accumulated water become widely-distributed on the CL surface and reduce the oxygen access to the CL, making flooding more easy to occur than when the MPL is added to the GDL. For the surface of the cathode CL (Figs. 11(a) and (b)), the MPL contributes to a reduction in gap sizes at the interface due to the finer structure of the MPL resulting in a closer contact between the CL and MPL, and the limited space available for water accumulation results in lower volumes of accumulated water (smaller areas covered by water) at the interface.

\subsection{Ice distribution after the shutdown at $-10^{\circ} \mathrm{C}$ cold startup}

An investigation of the cold startup characteristics by the authors [16] has shown that there is a temporary performance deterioration in the operation at $30{ }^{\circ} \mathrm{C}$ after a $-10{ }^{\circ} \mathrm{C}$ cold start shutdown, and it was proposed that this is caused by liquid water from the melted ice at the interface between the cathode CL and the MPL during the cold start operation flooding the cell at the subsequent operation. This performance deterioration could be recovered by dry nitrogen purging of the cell, and it was suggested that the amount of ice formed during the cold startup was larger than the amount of water accumulated during the ordinary operation above freezing temperatures. To validate this suggestion, a photographic analysis as also performed above in this study was made of the ice distribution on the cathode CL surface after $-10{ }^{\circ} \mathrm{C}$ shutdowns of the GDL with the MPL, and the result was compared with the liquid water distributions at the $35^{\circ} \mathrm{C}$ operation.

Before observation of the ice distribution, the temporary performance deterioration after the cold start shutdown was investigated using the cell with the MPL (the procedure is outlined in Fig. 2). At $35{ }^{\circ} \mathrm{C}$, the cell performance was measured with the humidity of both gases at $76 \% \mathrm{RH}$. The applied current density was initially increased to $0.5 \mathrm{~A} \mathrm{~cm}^{-2}$ for 300 seconds and then maintained at this current density, $0.5 \mathrm{~A} \mathrm{~cm}^{-2}$. Then after the dry and wet 
purging, the cell is cooled to $-10^{\circ} \mathrm{C}$, and cold startup at the current density of $0.04 \mathrm{~A} \mathrm{~cm}^{-2}$ was conducted. In the cold start operation, the cell voltage gradually decreased and a rapid voltage drop occurred after $77 \mathrm{~min}$ due to the freezing of the produced water, as reported in Ref. [16]. After the shutdown, the cell was heated to $35^{\circ} \mathrm{C}$ over about $10 \mathrm{~min}$, and then the cell performance was measured again at the same condition of $0.5 \mathrm{~A} \mathrm{~cm}^{-2}$ as before the cold start measurements (Fig. 2). Fig. 12 shows plots of the cell voltage and resistance before and after the cold start operation. The plots clearly show that the cell voltage after the shutdown of the cold startup is much lower than the value before the cold startup. The deteriorated voltage was reported in Ref. [16] to be recovered to the $35^{\circ} \mathrm{C}$ value by the dry nitrogen purge with flow rate of 3000 SCCM for more than 5 min. Similar cell resistances were recorded during all of the operations at $35^{\circ} \mathrm{C}$ before and after the cold startup in Fig. 12, and the difference in the cell voltage appears to be due to a concentration overpotential caused by accumulated water.

Next, a photographic analysis was made of the ice distribution on the cathode CL surface after $-10^{\circ} \mathrm{C}$ shutdowns of the GDL with the MPL. Fig. 13(a) is an example of a micrograph of the cathode CL surface and Fig. 13(b) the subtracted image (like in Fig. 4(c)) for the cell with an MPL after the cold start operation. Here, after operation at $0.04 \mathrm{~A} \mathrm{~cm}^{-2}$ and the shutdown, the cell was disassembled and the surface was observed. It is clearly shown that a larger ice covered area forms on the surface under the channels, compared with the situation after the operation at $35{ }^{\circ} \mathrm{C}$ in Figs. 7 and 9. The average area percentages of ice, calculated using the subtracted image, are 19.4, 4.9, and $12.2 \%$ for the surfaces under the channels, the lands, and for both the areas together, respectively, and these results show that larger ice covered area is formed at the CL and MPL interface than in the case of the $35^{\circ} \mathrm{C}$ operation in Fig. 10. From this it may be hypothesized that when a cell is operated in freezing temperatures relatively near to zero like at $-10^{\circ} \mathrm{C}$, the produced water readily accumulates in a supercooled state in the limited space between the CL and the MPL due to the low temperature, and after freezing the ice covered areas grow and expand beyond the limitations of the space available. After the cell is heated to a temperature above zero (here $35^{\circ} \mathrm{C}$ ), the ice melts, generating a large amount of liquid water at the interface, and this causes an obstacle to the oxygen supply to the cathode CL. Until the liquid water is evacuated by extensive purging or at high temperatures enabling the enlarged pore space to contract to the original state (that before the cold startup), the performance does not recover. These changes in the situation at the CL and MPL interface would explain the performance changes after the cold startup shown in Fig. 12, indicating a significant influence of the liquid water accumulated at the CL and MPL interface on the cell performance.

\subsection{Effect of interfacial structure at the CL and MPL contact}

The discussion above suggested that the interfacial gaps where the CL and the MPL are in contact allow liquid water accumulation, resulting in deterioration of the cell performance. This section investigates the effect of the interfacial structure at the contact between the CL and the MPL on the cell performance using two types of membrane electrode assemblies (MEAs) on the cathode side. These MEAs were experimentally produced by Asahi Glass Co., Ltd. [18,19]: one was manufactured by a conventional decal transfer method which combines 
a hydrophobic MPL coated GDL and a CL by hot-pressing, and the other was made by a gas diffusion electrode (GDE) method which directly coats a hydrophobic MPL surface with catalyst ink to form a CL at the cathode side (the decal transfer method was applied at the anode side) $[18,19]$. Because of the direct coating of the MPL with the CL, it may be assumed that there is an interfacial structure without large gaps between the CL and the MPL with the GDE.

The polarization curves for the MEAs by the decal and the GDE are shown in Fig. 14. The operating conditions were the same as in the experiment in Fig. $5\left(35^{\circ} \mathrm{C}, 100 \%\right.$ and $76 \%$ $\mathrm{RH})$. With the MEA based on the decal method, the performance levels in Fig. 14 are equivalent to those in Fig. 5. The cell voltages with the decal are similar at both relative humidity conditions even under high current densities, and reach around $1.2 \mathrm{~A} \mathrm{~cm}^{-2}$. For the MEA by the GDE method, the cell voltages are less affected by the humidity conditions investigated here, and extend to around $2.0 \mathrm{~A} \mathrm{~cm}^{-2}$ without a voltage drop at high current densities. This shows that the MEA by the GDE method is tolerant to flooding. The firm interface between the CL and the MPL contributes to limit water accumulation on the CL surface, and realizes the higher current density operation without any voltage drop due to the concentration overpotential caused by the condensed water. This suggests the importance of a fine contact between CL and MPL (contact without gaps) for better performance under high current density conditions. The appropriateness of the design of the MPL coated GDL becomes increasingly important when severe flooding conditions are expected. This also supports the assumption that the interfacial gaps between the CL and the MPL provide the space where liquid water accumulates, and the MPL plays a role in suppressing the water accumulation at the interface, resulting in the improvements in tolerance to flooding.

\section{Conclusions}

The mechanism of MPLs to suppress water flooding in a PEFC is discussed based on the results of observations of the liquid water distribution at the cathode CL surface captured in ice form with a freezing method. The temporary performance deterioration after cold start shutdown and the effect of the interfacial structure at the CL and MPL interface were also investigated. The major conclusions may be summarized as follows:

1. The area covered with generated water at the cathode CL surface, captured in ice form, with the MPL increases with increasing current density and relative humidity of the supplied gases. The ice covered area is much larger without an MPL than with an MPL, and this corresponds to the observed changes in the cell voltage: a higher ice cover ratio on the entire surface decreases the cell voltage.

2. The interfacial gaps between the CL and the GDL provide space for liquid water to accumulate, and the MPL functions to suppress this water accumulation at the interface due to the finer and closer contact with the CL. The produced water may pass through the MPL in vapor form, and the MPL avoids accumulation of liquid water at the CL surface further improving the tolerance to flooding.

3. After the shutdown at cold startup at $-10^{\circ} \mathrm{C}$, a larger ice covered area is observed on the cathode CL surface, than after the operation at $35^{\circ} \mathrm{C}$. This would be caused by the special conditions of the cold start, low temperature and ice growth filling the constricted spaces 
between the CL and the MPL, resulting in the temporary performance deterioration in the subsequent operation at $35^{\circ} \mathrm{C}$ after the shutdown.

4. With MEAs made by a GDE method there are increases in the cell voltage at higher current density conditions than in cells with an MEA made by the decal transfer method. This suggests that the fine contact between the CL and the MPL, the relative absence of gaps, in the MEA using the GDE method contributes to prevent the produced water from accumulating on the CL interface, and mitigates performance deterioration arising from flooding.

\section{Acknowledgment}

The authors thank Asahi Glass Co., Ltd. for provision of the MEAs used in section 3.5 with the valuable information for their use. This research was supported by JSPS KAKENHI Grant Numbers 21360089, 24360076.

\section{References}

[1] U. Pasaogullari, C.-Y. Wang, K.S. Chen, J. Electrochem. Soc. 152 (8) (2005) A1574-A1582.

[2] A.Z. Weber, J. Newman, J. Electrochem. Soc. 152 (4) (2005) A677-A688.

[3] H.N. Atiyeh, K. Karan, B. Peppley, A. Phoenix, E. Halliop, J. Pharoah, J. Power Sources 170 (2007) 111-121.

[4] H. Li, Y. Tang, Z. Wang, Z. Shi, S. Wu, D. Song, J. Zhang, K. Fatih, J. Zhang, H. Wang, Z. Liu, R. Abouatallah, A. Mazza, J. Power Sources 178 (2008) 103-117.

[5] J.T. Gostick, M.A. loannidis, M.W. Fowler, M.D. Prizker, Electrochem. Commun. 11 (2009) 576-579.

[6] J.P. Owejan, J.E. Owejan, W. Gu, T.A. Trabold, T.W. Tighe, M.F. Mathias, J. Electrochem. Soc. 157 (10) (2010) B1456-B1464.

[7] F.E. Hizir, S.O. Ural, E.C. Kumbur, M.M. Mench, J. Power Sources 195 (2010) 3463-3471.

[8] T. Swamy, E.C. Kumbur, M.M. Mench, J. Electrochem. Soc. 157 (1) (2010) B77-B85.

[9] H. Bajpai, M, Khandelwal1, E. C. Kumbur, and M. M. Mench, J. Power Sources 195 (2010) 4196-4205.

[10]P. Boillat, D. Kramer, B. C. Seyfang, G. Frei, E. Lehmann, G. G. Scherer, A. Wokaun, Y. Ichikawa, Y. Tasaki, K. Shinohara, Electrochem. Commun. 10 (2008) 546-550.

[11] A. Turhan, S. Kim, M. Hatzell, M.M. Mench, Electrochem. Acta. 55 (2010) 2734-2745.

[12] C. Hartnig, I. Manke, R. Kuhn, N. Kardjilov, J. Banhart, W. Lehnert, Appl. Phys. Lett. 92 (2008) 134106.

[13] T. Sasabe, P. Deevanhxay, S. Tsushima, S. Hirai, J. Power Sources 196 (2011) 8197-8206.

[14] J.H. Nam, K.-J. Lee, G.-S. Hwang, C.-J. Kim, M. Kaviany, Int. J. Heat and Mass Transfer 52 (2009) 2779-2791.

[15] Y. Aoyama, K. Suzuki, Y. Tabe, T. Chikahisa, Electrochem. Commun. 41 (2014) 72-75.

[16] Y. Tabe, M. Saito, K. Fukui, T. Chikahisa, J. Power Sources 208 (2012) 366-373. 
[17] K.S.S. Naing, Y. Tabe, T. Chikahisa, J. Power Sources 196 (2011) 2584-2594.

[18] T. Tanuma, J. Electrochem. Soc. 157 (12) (2010) B1809-B1813.

[19] T. Tanuma, S. Kinoshita, J. Electrochem. Soc. 161 (1) (2014) F94-F98. 


\section{Captions}

Table 1 Percentages of ice covered areas on the cathode CL surface at $35^{\circ} \mathrm{C}$ operation with an MPL at $0.7 \mathrm{~A} \mathrm{~cm}^{-2}$ and $100 \% \mathrm{RH}$.

Table 2 Percentages of ice covered areas on the cathode CL surface at $35{ }^{\circ} \mathrm{C}$ operation without an MPL at $0.7 \mathrm{~A} \mathrm{~cm}^{-2}$ and $100 \% \mathrm{RH}$.

Fig. 1. The bipolar plate with straight channels used in the investigations here (left), and photo of the inside of the thermostatic chamber (right).

Fig. 2. Flow chart of the experimental procedures for the operation at $35{ }^{\circ} \mathrm{C}$, the direct observations of the cathode component surfaces, and the cold start operation.

Fig. 3. Method for identifying ice on the CL surface by binary image processing; (a) micrograph of the CL surface, (b) image histogram for the brightness of (a), images showing ice appearing (c) darker and (d) brighter in (a), and (e) image showing all ice (combination of (c) and (d)).

Fig. 4. Binary images of the CL surface (a) with and (b) without the ice, and (c) subtracted image ((b) is subtracted from (a)) showing only the ice covered areas $\left(0.7 \mathrm{~A} \mathrm{~cm}^{-2}\right.$, $76 \% \mathrm{RH})$.

Fig. 5. Polarization curves with and without the MPL at $35{ }^{\circ} \mathrm{C}$ operation $(100 \%$ and $76 \%$ $\mathrm{RH})$.

Fig. 6. Plot of cell voltages and resistances for the operation at $35^{\circ} \mathrm{C}$ for current densities of (a) 0.5 and (b) $0.7 \mathrm{~A} \mathrm{~cm}^{-2}$, both with RH $100 \%$.

Fig. 7. Micrograph and processed images of the water distribution on the cathode CL surface captured in ice form with the freezing method at $35^{\circ} \mathrm{C}$ operation with the MPL at $0.7 \mathrm{~A} \mathrm{~cm}^{-2}$ and $100 \% \mathrm{RH}$ (location number 4 in Table 1); (a) micrograph of the CL surface, binary images (b) with and (c) without the ice, and (d) subtracted image.

Fig. 8. Micrograph and processed images of the water distribution on the cathode CL surface captured in ice form with the freezing method at $35^{\circ} \mathrm{C}$ operation without the MPL at $0.7 \mathrm{~A} \mathrm{~cm}^{-2}$ and $100 \% \mathrm{RH}$ (location number 4 in Table 2); (a) micrograph of the CL surface, binary images (b) with and (c) without the ice, and (d) subtracted image.

Fig. 9. Subtracted images of water distribution on the cathode CL surface captured in ice form with the freezing method at $35{ }^{\circ} \mathrm{C}$ operation with the MPL under various conditions: (a) $100 \% \mathrm{RH}, 0.5 \mathrm{~A} \mathrm{~cm}^{-2}$, (b) $76 \% \mathrm{RH}, 0.7 \mathrm{~A} \mathrm{~cm}^{-2}$, and (c) $76 \% \mathrm{RH}$, $0.5 \mathrm{~A} \mathrm{~cm}^{-2}$.

Fig. 10. Average percentages of ice covered areas on the cathode CL surface, calculated using the subtracted images, under the channels, under the lands, and for the total of the areas for cells (a) with and (b) without an MPL.

Fig. 11. Schematic representation of the water distribution on a cathode CL surface for cells: water accumulated (a) under channels with an MPL and (b) under channels and lands without an MPL.

Fig. 12. Cell voltages and resistances for the $35^{\circ} \mathrm{C}$ operation before and after a cold start shutdown with operation at $-10^{\circ} \mathrm{C}$. 
Fig. 13. The ice distribution on the cathode CL surface after the cold start operation at $-10^{\circ} \mathrm{C}$;

(a) micrograph of the CL surface and (b) subtracted image (the binary image without ice is subtracted from that with ice).

Fig. 14. Polarization curves for the MEAs by the decal and the GDE methods at $35{ }^{\circ} \mathrm{C}$ operation (100\% and 76\% RH). 
Table 1 Percentages of ice covered areas on the cathode CL surface at $35^{\circ} \mathrm{C}$ operation with an MPL at $0.7 \mathrm{~A} \mathrm{~cm}^{-2}$ and $100 \% \mathrm{RH}$.

\begin{tabular}{|c|c|c|c|c|c|c|}
\hline \multirow[b]{2}{*}{$\begin{array}{c}\text { Location } \\
\text { number }\end{array}$} & \multicolumn{3}{|c|}{ Ice coverd area in image with ice (\%) } & \multicolumn{3}{|c|}{ Ice coverd area calculated using subtracted image $(\%)$} \\
\hline & Under channels & Under lands & Both areas & Under channels & Under lands & Both areas \\
\hline 1 & 10.5 & 2.1 & 6.3 & 10.3 & 2.3 & 6.3 \\
\hline 2 & 15.1 & 1.4 & 8.2 & 15.3 & 1.5 & 8.4 \\
\hline 3 & 15.3 & 1.4 & 8.3 & 13.0 & 0.9 & 7.0 \\
\hline 4 & 12.1 & 1.8 & 7.0 & 12.6 & 1.5 & 7.0 \\
\hline Average & 13.3 & 1.7 & 7.5 & 12.8 & 1.6 & 7.2 \\
\hline
\end{tabular}


Table 2 Percentages of ice covered areas on the cathode CL surface at $35^{\circ} \mathrm{C}$ operation without an MPL at $0.7 \mathrm{~A} \mathrm{~cm}^{-2}$ and $100 \% \mathrm{RH}$.

\begin{tabular}{|c|c|c|c|c|c|c|}
\hline \multirow[b]{2}{*}{$\begin{array}{c}\text { Location } \\
\text { number }\end{array}$} & \multicolumn{3}{|c|}{ Ice coverd area in image with ice (\%) } & \multicolumn{3}{|c|}{ Ice coverd area calculated using subtracted image $(\%)$} \\
\hline & Under channels & Under lands & Both areas & Under channels & Under lands & Both areas \\
\hline 1 & 7.1 & 12.7 & 9.9 & 4.5 & 8.6 & 6.5 \\
\hline 2 & 7.7 & 14.9 & 11.3 & 6.2 & 8.0 & 7.1 \\
\hline 3 & 12.5 & 14.7 & 13.6 & 12.3 & 13.0 & 12.6 \\
\hline 4 & 9.6 & 15.0 & 12.3 & 9.4 & 10.5 & 9.9 \\
\hline Average & 9.2 & 14.3 & 11.8 & 8.1 & 10.0 & 9.1 \\
\hline
\end{tabular}



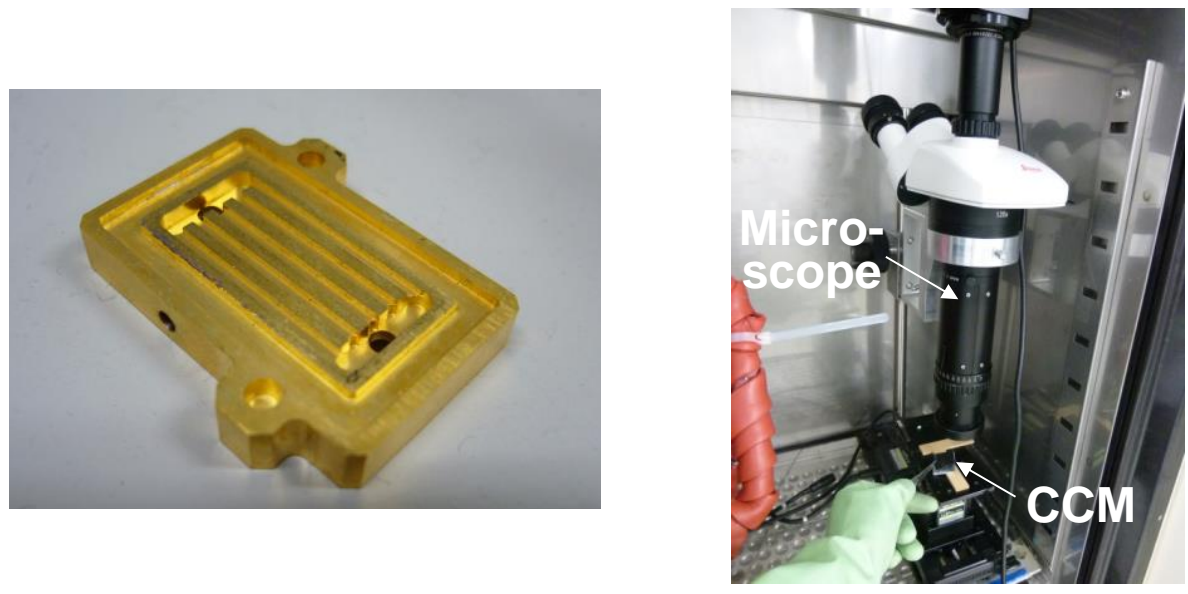

Fig. 1. The bipolar plate with straight channels used in the investigations here (left), and photo of the inside of the thermostatic chamber (right). 


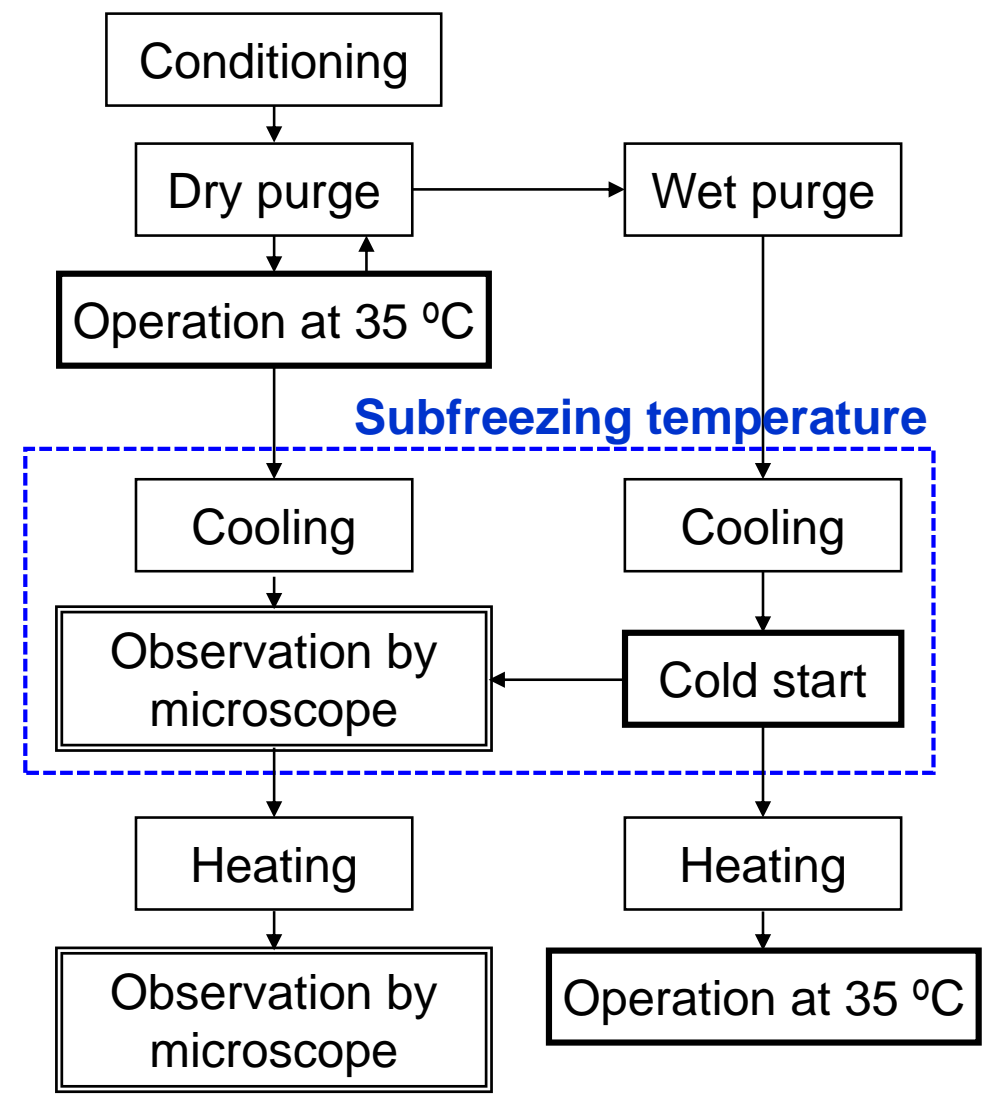

Fig. 2. Flow chart of the experimental procedures for the operation at $35^{\circ} \mathrm{C}$, the direct observations of the cathode component surfaces, and the cold start operation. 
(a) Micrograph of CL surface

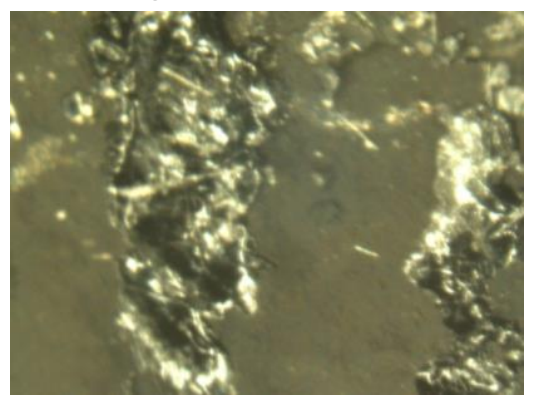

(c) Ice appearing darker

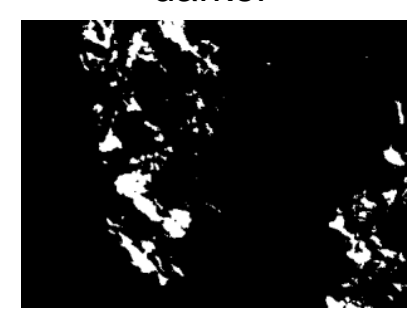

(d) Ice appearing brighter

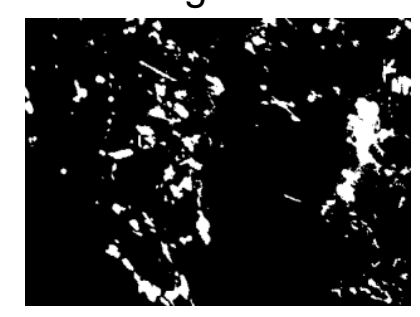

(b) Histogram

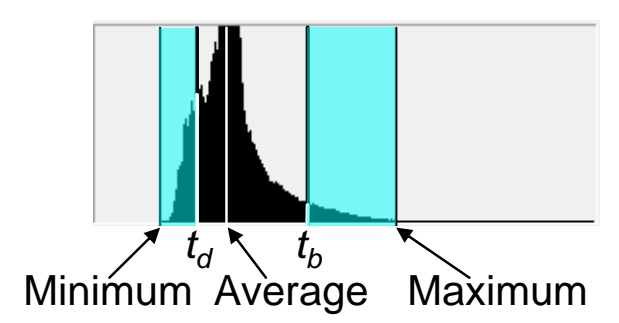

(e) Ice identified by combination

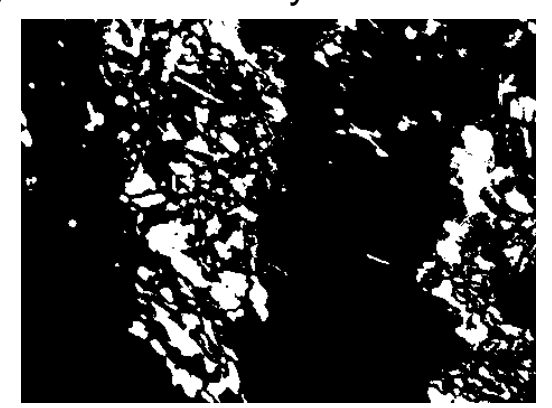

Fig. 3. Method for identifying ice on the CL surface by binary image processing; (a) micrograph of the CL surface, (b) image histogram for the brightness of (a), images showing ice appearing (c) darker and (d) brighter in (a), and (e) image showing all ice (combination of (c) and (d)). 
(a) With ice

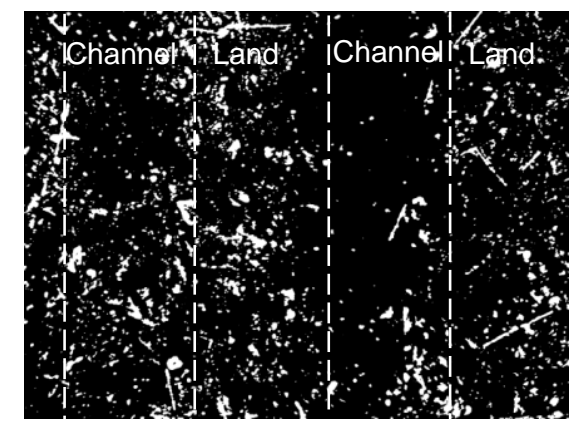

(b) Without ice

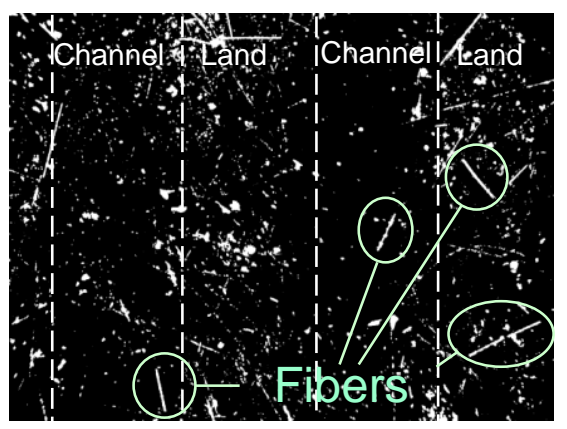

(c) Subtracted

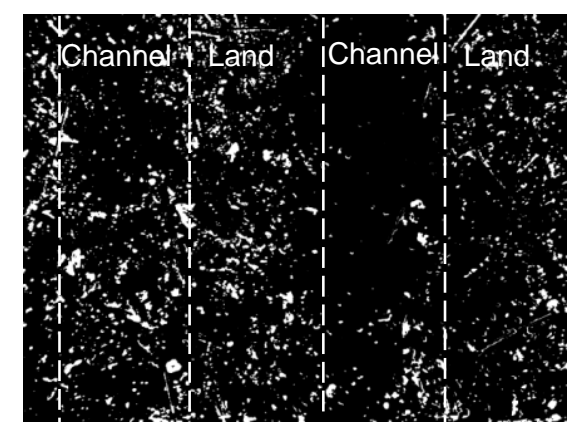

Fig. 4. Binary images of the CL surface (a) with and (b) without the ice, and (c) subtracted image ((b) is subtracted from (a)) showing only the ice covered areas $\left(0.7 \mathrm{~A} \mathrm{~cm}^{-2}, 76 \% \mathrm{RH}\right)$. 


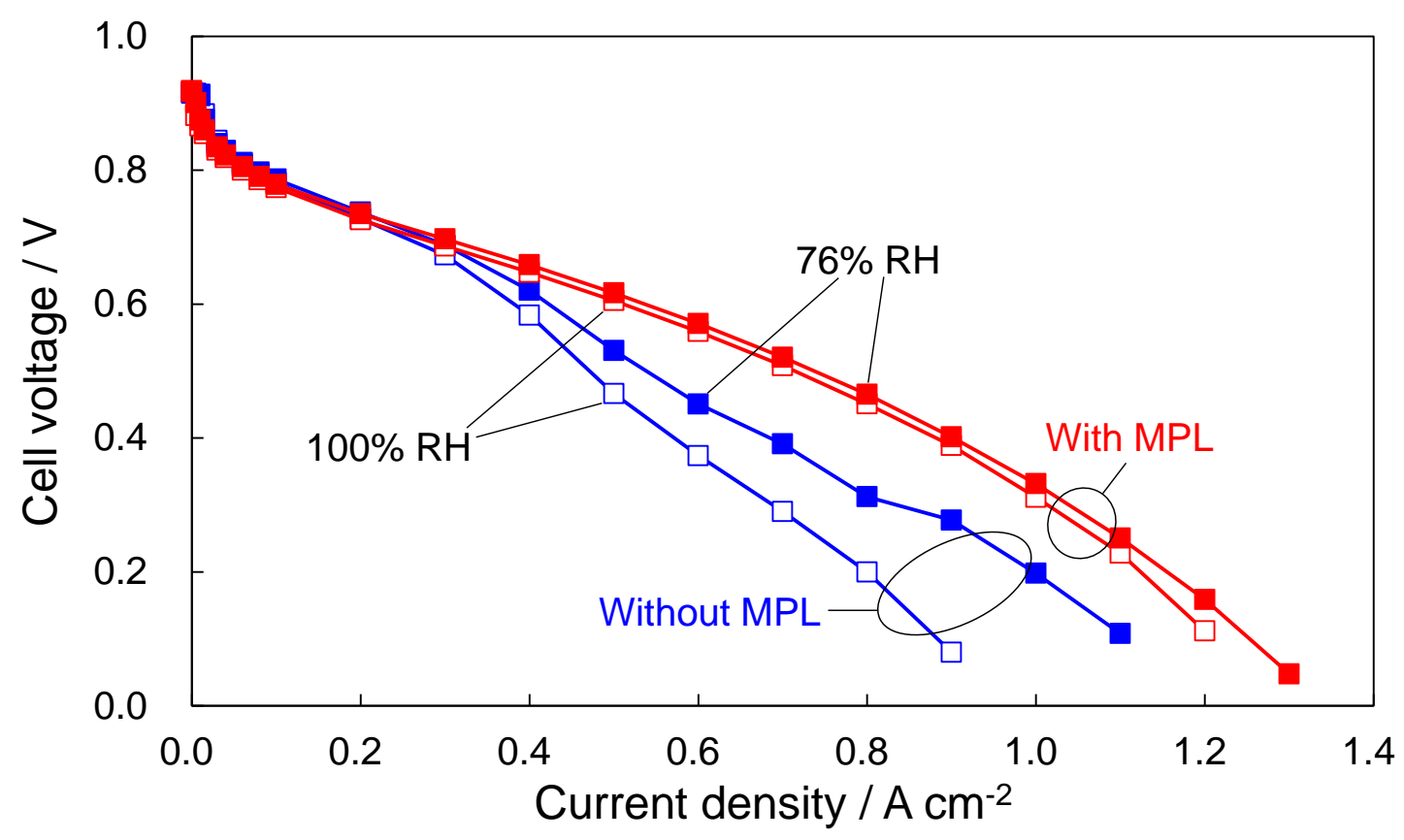

Fig. 5. Polarization curves with and without the MPL at $35{ }^{\circ} \mathrm{C}$ operation $(100 \%$ and $76 \%$ $\mathrm{RH})$. 
(a)

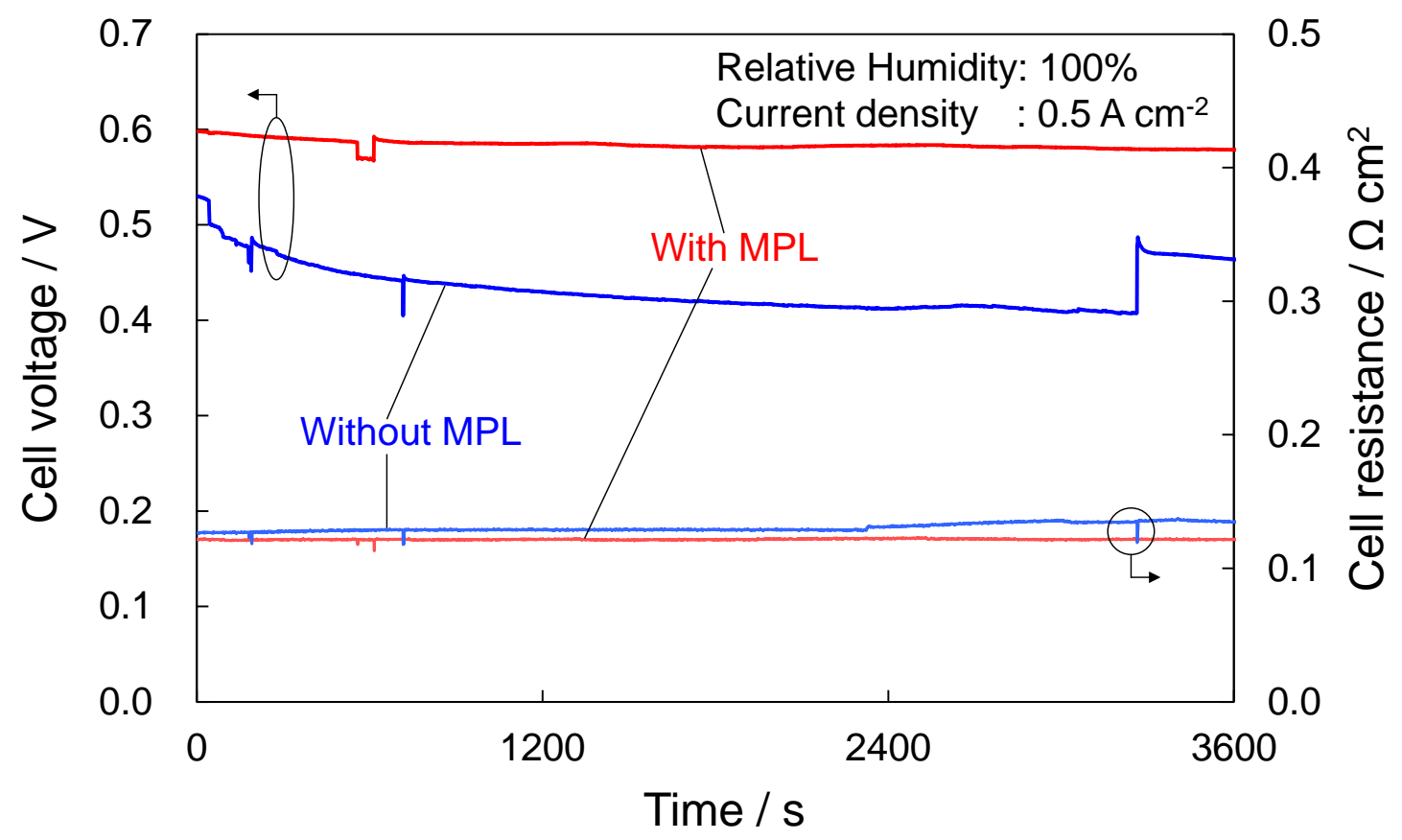

(b)

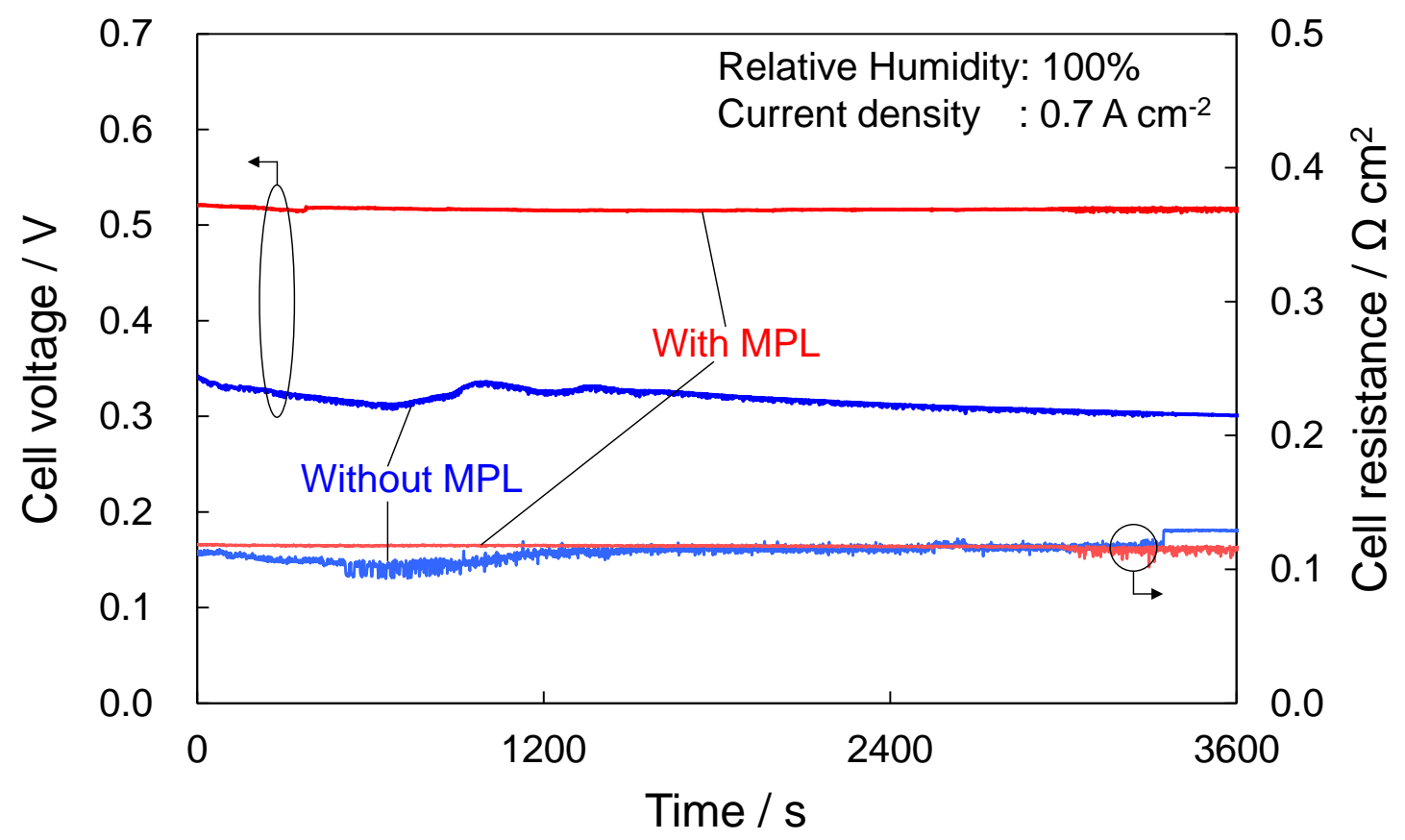

Fig. 6. Plot of cell voltages and resistances for the operation at $35^{\circ} \mathrm{C}$ for current densities of (a) 0.5 and (b) $0.7 \mathrm{~A} \mathrm{~cm}^{-2}$, both with RH $100 \%$. 


\section{(a) Micrograph}

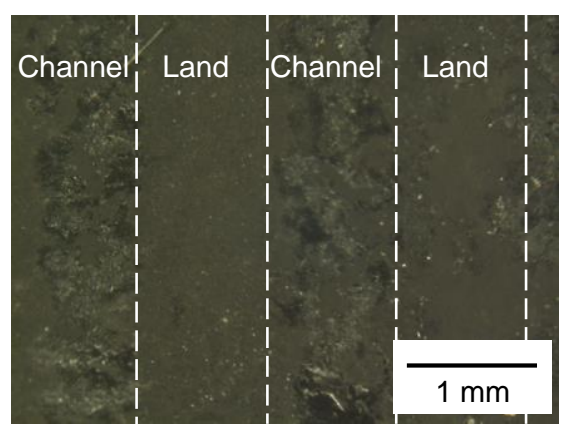

(b) Image with ice

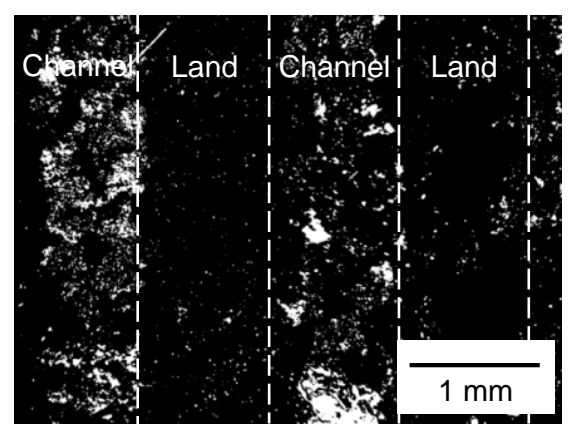

(c) Image without ice

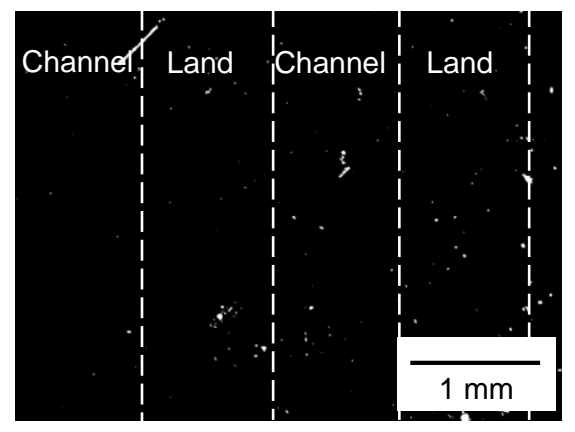

(d) Subtracted image

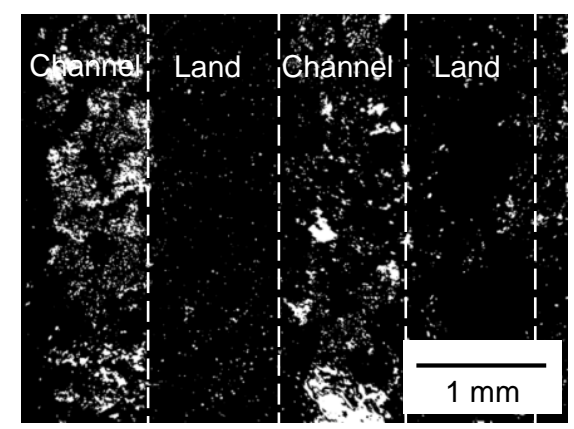

Fig. 7. Micrograph and processed images of the water distribution on the cathode CL surface captured in ice form with the freezing method at $35^{\circ} \mathrm{C}$ operation with the MPL at $0.7 \mathrm{~A} \mathrm{~cm}^{-2}$ and 100\% RH (location number 4 in Table 1); (a) micrograph of the CL surface, binary images (b) with and

(c) without the ice, and (d) subtracted image. 


\section{(a) Micrograph}

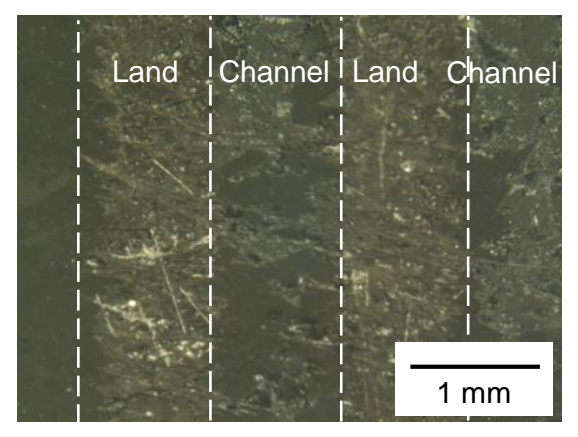

(b) Image with ice

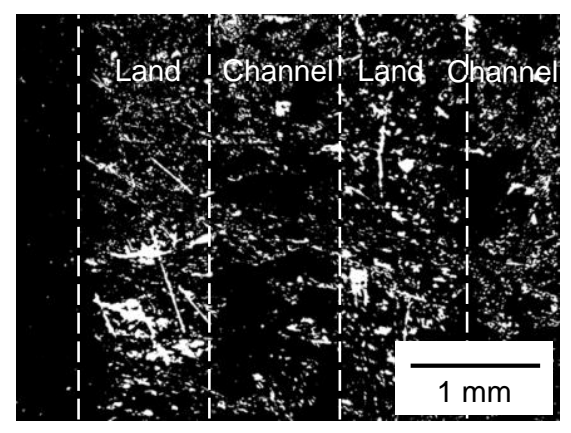

(c) Image without ice

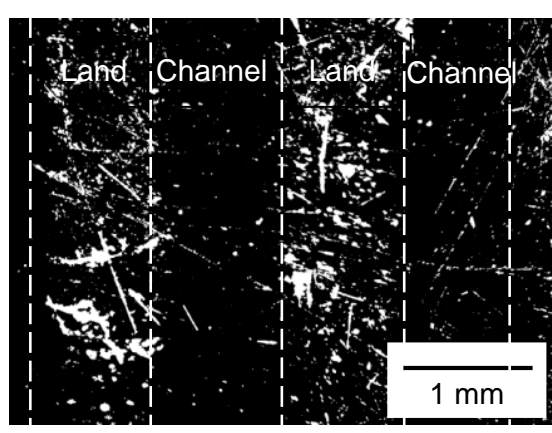

(d) Subtracted image

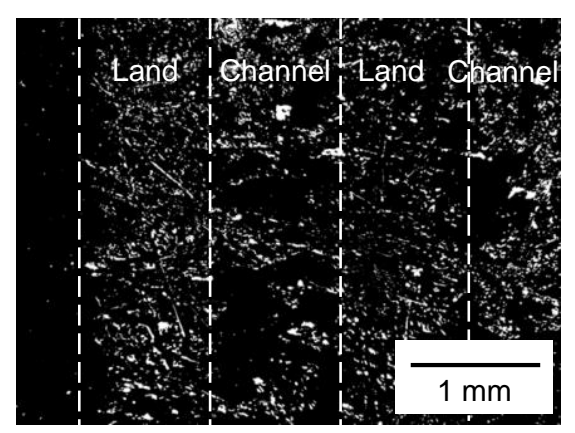

Fig. 8. Micrograph and processed images of the water distribution on the cathode $\mathrm{CL}$ surface captured in ice form with the freezing method at $35^{\circ} \mathrm{C}$ operation without the MPL at $0.7 \mathrm{~A} \mathrm{~cm}^{-2}$ and $100 \% \mathrm{RH}$ (location number 4 in Table 2); (a) micrograph of the CL surface, binary images (b) with and (c) without the ice, and (d) subtracted image. 
(a) $100 \% \mathrm{RH}, 0.5 \mathrm{~A} \mathrm{~cm}^{-2}$

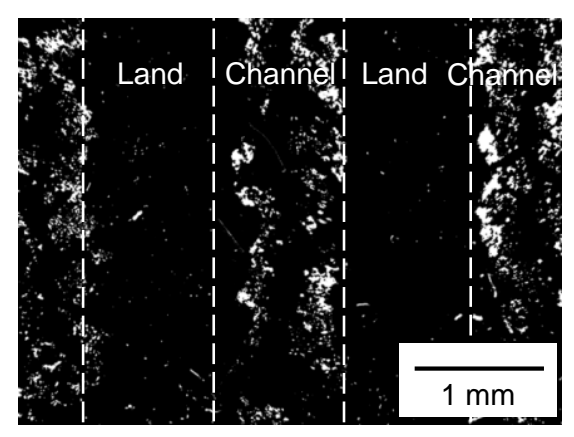

(b) $76 \% \mathrm{RH}, 0.7 \mathrm{~A} \mathrm{~cm}^{-2}$

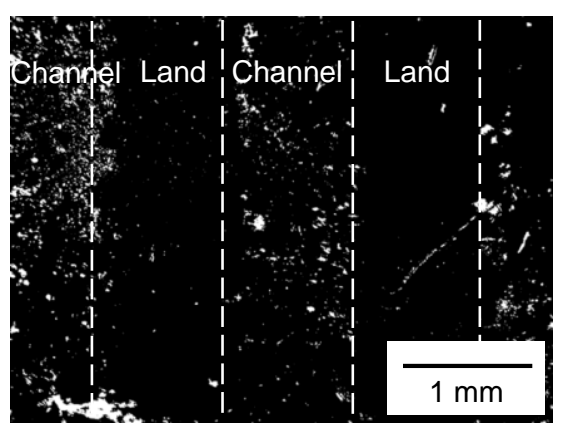

(c) $76 \% \mathrm{RH}, 0.5 \mathrm{~A} \mathrm{~cm}^{-2}$

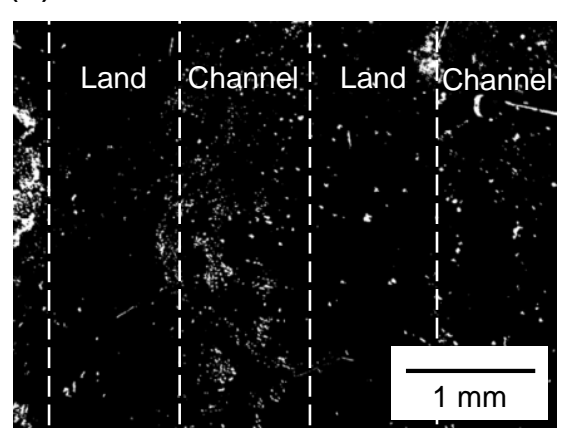

Fig. 9. Subtracted images of water distribution on the cathode $\mathrm{CL}$ surface captured in ice form with the freezing method at $35^{\circ} \mathrm{C}$ operation with the MPL under various conditions: (a) $100 \% \mathrm{RH}, 0.5 \mathrm{~A} \mathrm{~cm}^{-2}$, (b) $76 \% \mathrm{RH}, 0.7 \mathrm{~A} \mathrm{~cm}^{-2}$, and (c) $76 \% \mathrm{RH}, 0.5 \mathrm{~A} \mathrm{~cm}^{-2}$. 
(a)

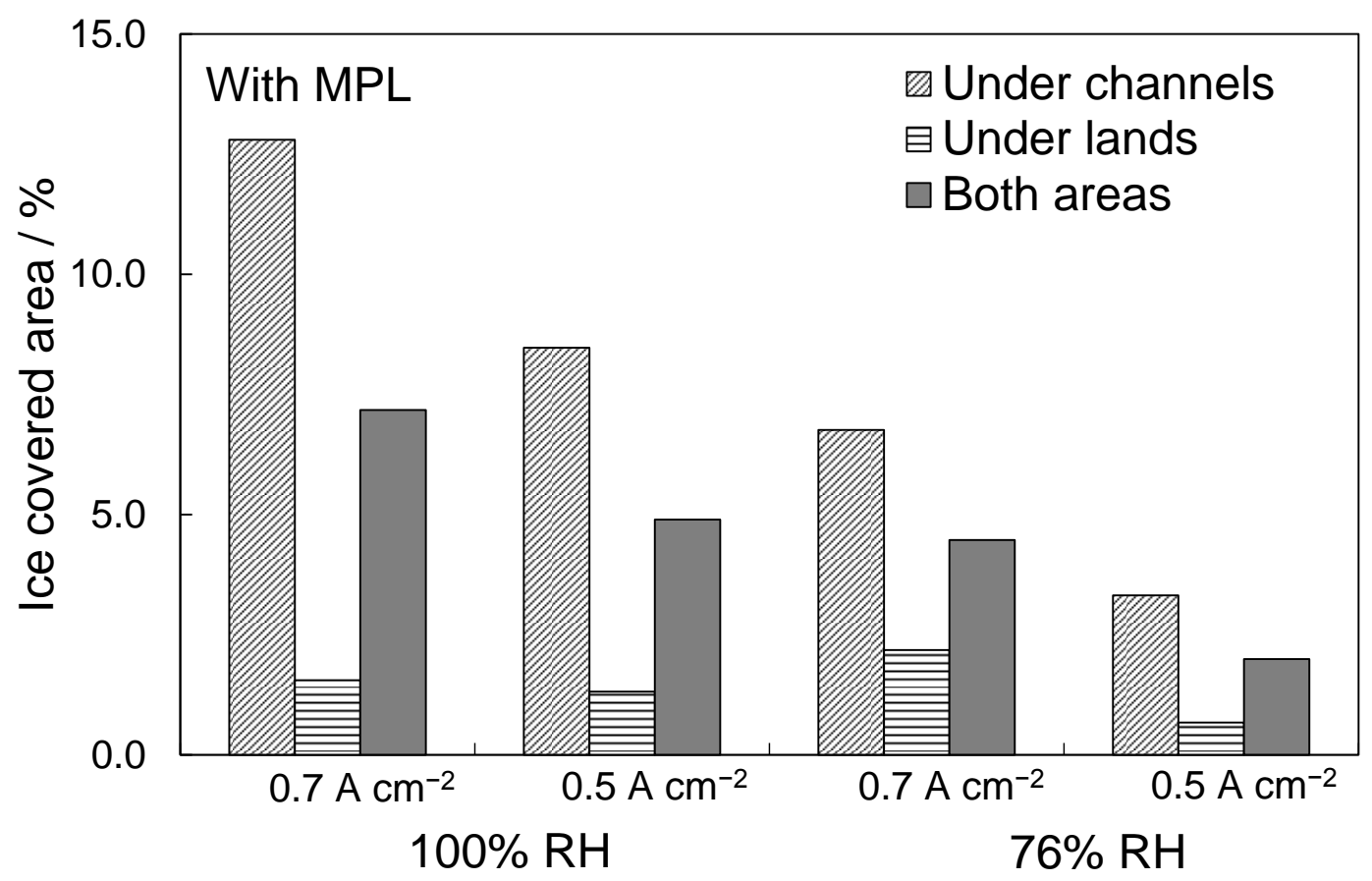

(b)

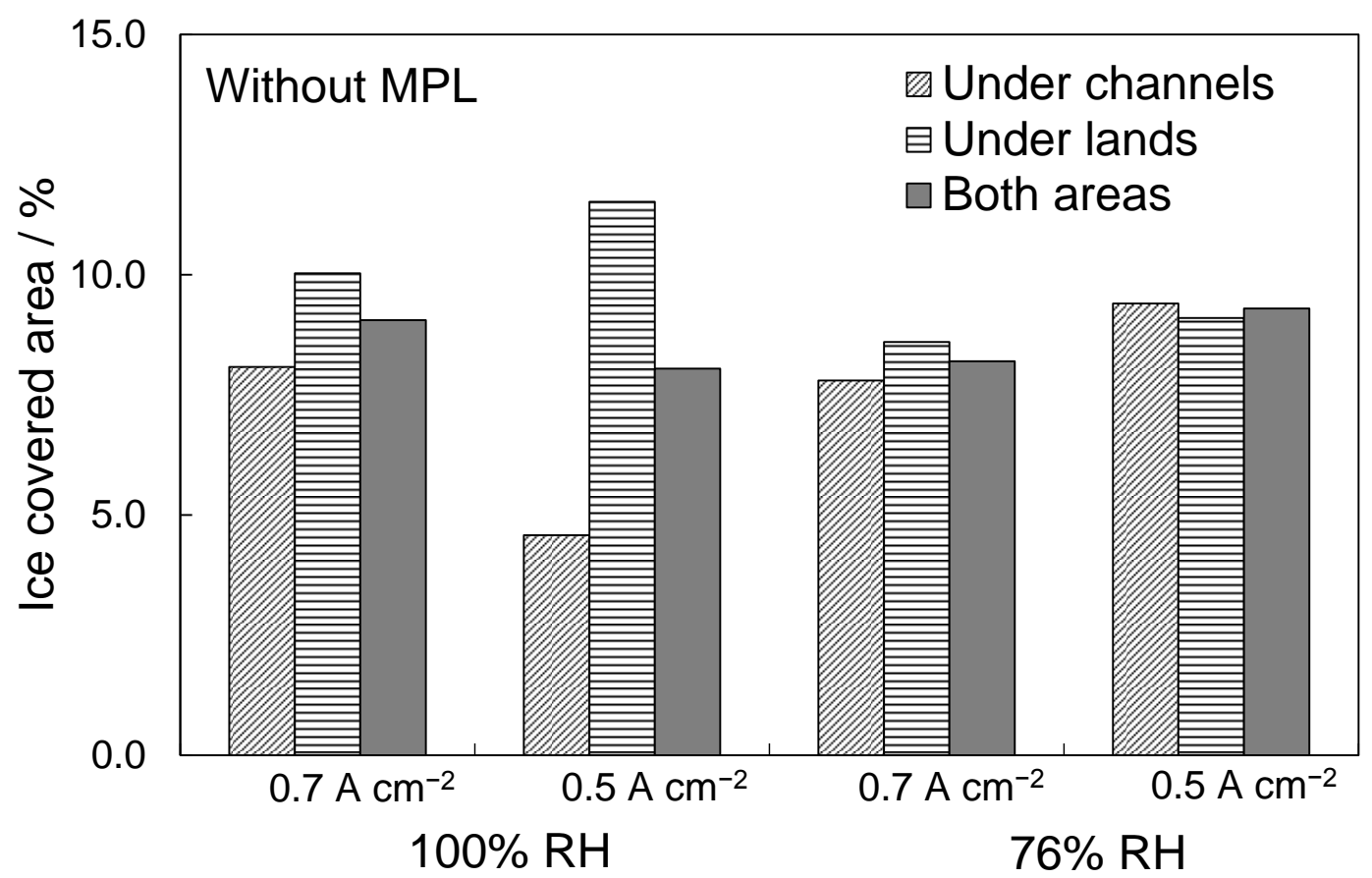

Fig. 10. Average percentages of ice covered areas on the cathode CL surface, calculated using the subtracted images, under the channels, under the lands, and for the total of the areas for cells (a) with and (b) without an MPL. 
(a) With MPL

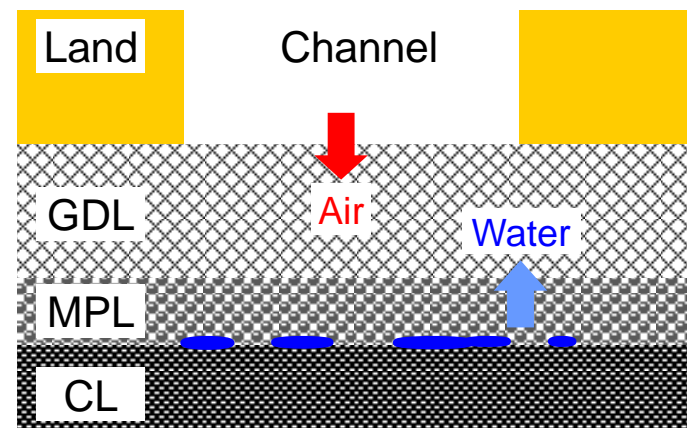

(b) Without MPL

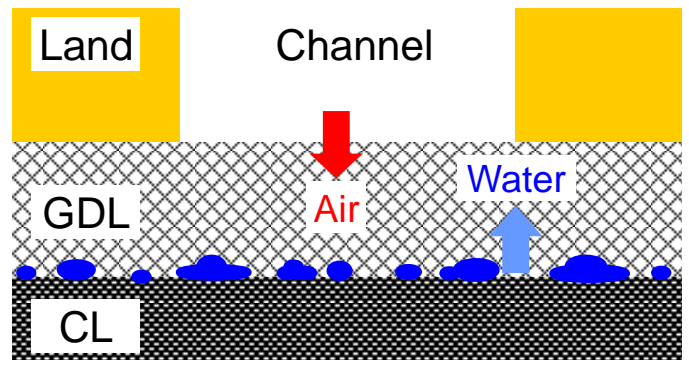

Fig. 11. Schematic representation of the water distribution on a cathode CL surface for cells: water accumulated (a) under channels with an MPL and (b) under channels and lands without an MPL. 


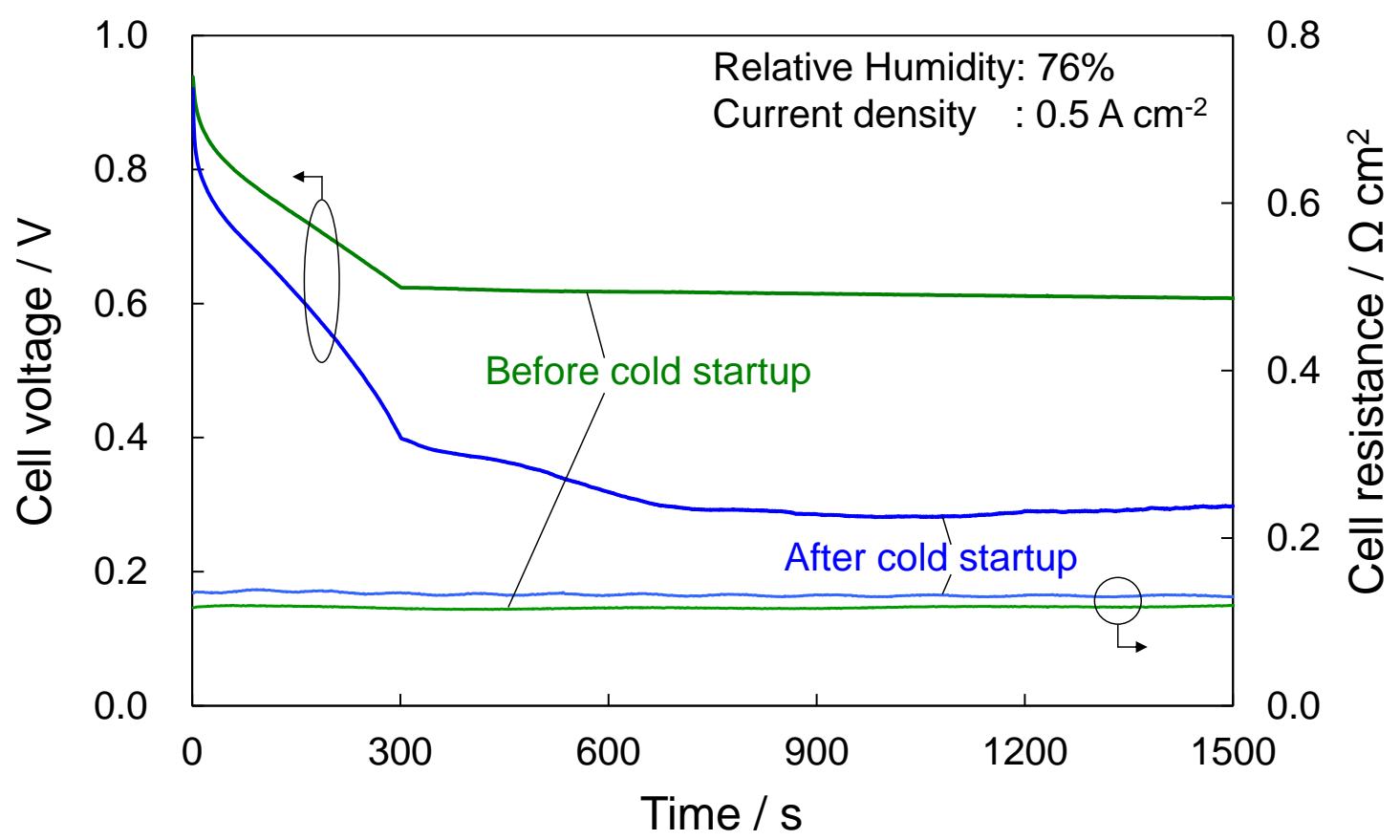

Fig. 12. Cell voltages and resistances for the $35^{\circ} \mathrm{C}$ operation before and after a cold start shutdown with operation at $-10^{\circ} \mathrm{C}$. 
(a) Micrograph

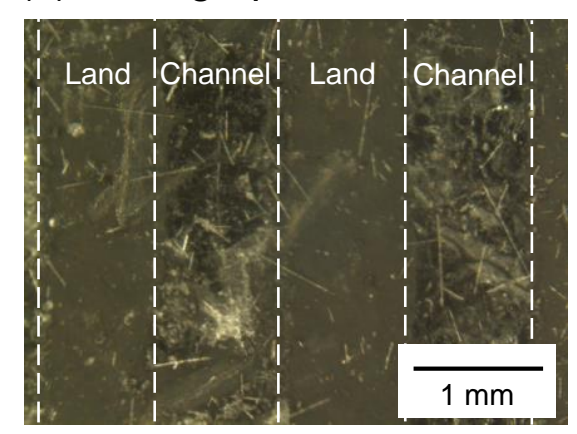

(b) Subtracted image

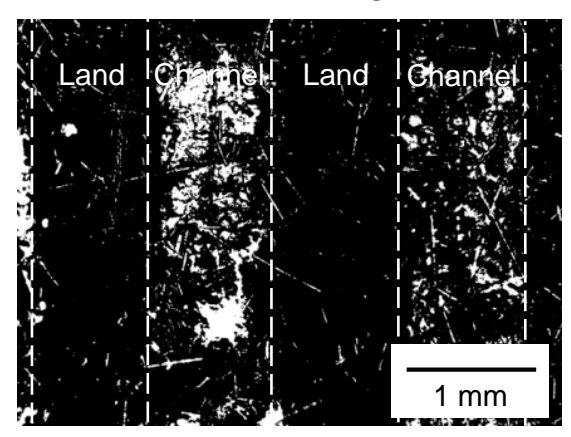

Fig. 13. The ice distribution on the cathode $C L$ surface after the cold start operation at $-10{ }^{\circ} \mathrm{C}$; (a) micrograph of the CL surface and (b) subtracted image (the binary image without ice is subtracted from that with ice). 


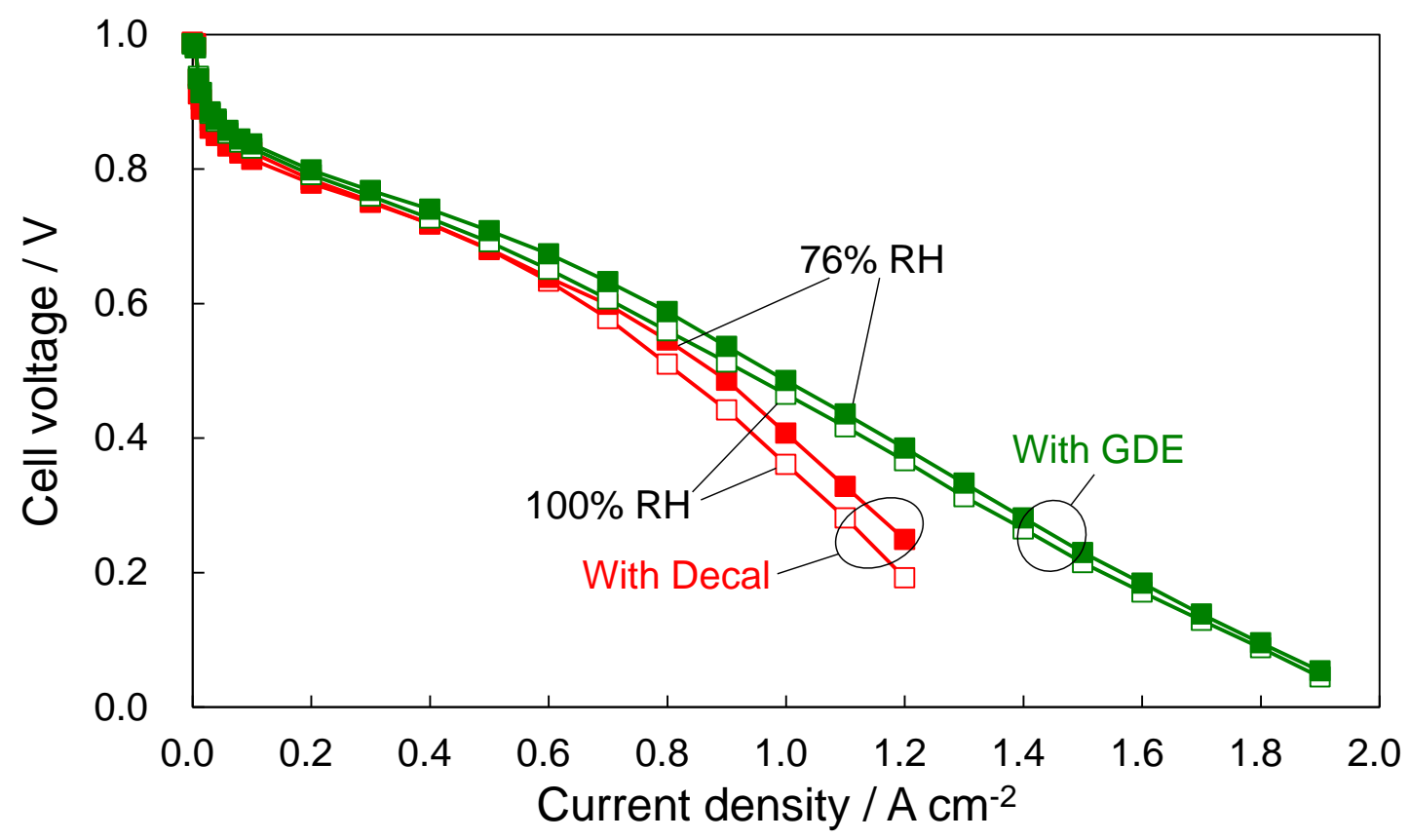

Fig. 14. Polarization curves for the MEAs by the decal and the GDE methods at $35^{\circ} \mathrm{C}$ operation (100\% and $76 \% \mathrm{RH})$. 